\title{
Root colonization: imperative mechanism for efficient plant protection and growth
}

\begin{abstract}
Agriculture is important for food security, and is vulnerable to biotic and abiotic factors are responsible for lower agricultural services worldwide. To combat problems of pests and diseases occurrence and low soil productivity, farmers use conventional agrochemicals. Continuous and injudicious use of agrochemicals has detrimentally affected the soil, flora, fauna, wildlife, water bodies, air and human health. To overcome the challenges posed by ecological stresses sustainable approaches are required. Application of Agriculturally important microorganisms (AIMs) is considered as most eco-friendly approach. AIMs are naturally occurring beneficial microorganisms that sustainably protect plants from threats of pests and pesticides; promote plant growth and alleviate abiotic stresses. AIMs that reside in and around plant roots are termed as Rhizospheric microorganisms. Many rhizospheric microbes are known to support plant growth promotion and biocontrol in various economically important crops using plethora of mechanisms. Root colonization is considered as an important strategy of rhizospheric microbes for biocontrol and plant growth promotion. This review reveals the emerging insight on a process of root colo most crucial and prime step for biocontrol of plant diseases in addition to plant growth promotion; amelioration of abiotic stress and bioremediation nization displayed by rhizospheric microorganisms.
\end{abstract}

Volume 3 Issue 4 - 2018

\section{Swati Sachdev, Rana Pratap Singh}

Department of Environmental Science, Babasaheb Bhimrao

Ambedkar University, India

Correspondence: Rana Pratap Singh, Department of Environmental Science, School for Environmental Sciences, Babasaheb Bhimrao Ambedkar University,Vidya vihar, Raebareli Road, Lucknow-226025, India, Tel +91-9889-1218-23, Email cceseditor@gmail.com

Received: November 13, 2017 | Published: July 10, 2018

Keywords: agriculturally important microorganisms, agrochemicals, biocontrol, ecological stress, plant growth promotion

\section{Introduction}

Agriculture is an important sector that determines the health and food security of a country during all the odds. Plants have suffered with productivity and yield losses and threats by several biotic and abiotic ecological factors, e.g. plant diseases, pest manifestation, flood, drought, heat waves, etc. These losses are gradually increasing due to rapid change in climatic odds and disasters due to high built up of greenhouse gases of anthropogenic origin mainly due to industrialization, and urbanization, etc. To produce safe food to feed increasing population, the agricultural practices have been entirely dependent on conventional means such as use of agrochemicals. Overuse of agrochemicals coupled with uncertainty in climatic behavior, resource depletion, land fragmentation and degradation, lack of awareness among farmers, increased incidence of abiotic stress and accelerated rate of pests and disease occurrence has challenged agricultural sustainability very seriously in the recent past. ${ }^{1-4}$ Sustainable agriculture is an agricultural practice that maintains world's food security to feed growing population without disrupting ecological integrity. A paradigmatic shift is necessary to attain agricultural sustainability and providing food security to growing global population of 9-10 million by 2050 by doubling food production (70-100\%). ${ }^{5,6}$ Adoption of integrated pest and nutrient management methods, agroforestry, integrated waste management for livestock production, use of agriculturally important microorganisms (AIMs) present avenues for sustainable agriculture and reduces negative environmental externalities. ${ }^{5,7}$

\section{Rhizosphere: a site for plant-microbe interaction}

The soil has most influential effect on crop performance, preferably in "Rhizosphere", the zone surrounding plant roots, which is a tempting denizen for soil borne microorganisms that in order to sustain themselves display competition as well as co-operation with other existing living entities. Agriculturally important microorganisms (AIMs) show plant-microbe relationship and possess ability to alleviate ecological stresses. Many AIMs are rhizospheric inhabitants, endowed with some beneficial traits termed as Rhizospheric microorganisms. Beneficial rhizospheric microorganisms are saints in soil that nullifies the negative effects of other deleterious microorganisms and persisting hostile abiotic conditions, impeding on growth and productivity of plants by recruiting themselves in service of plants residing under same niche with their inherent multifarious valuable traits. Harnessing potential of such agriculturally important rhizospheric microorganisms can pave a way for sustainable agriculture. The plant growth promoting Rhizobacteria (PGPR) and plant growth promoting fungi (PGPF) are some AIMs that are generally found in rhizosphere (vicinity of roots) or associated with plant roots showing endophytic relationship.

\section{Root colonization: most crucial mechanism for} consistent beneficial performance

Root colonization by rhizospheric microorganisms is prior among all mechanisms that determine their efficiency to increase plant growth, biocontrol potential and ability to induce tolerance against abiotic stresses. ${ }^{8,9}$

The root colonization by microorganisms involves series of steps:

I. Recognition;

II. Adherence to the surface of root and penetration in case of endophytes;

III. Colonization in or around the roots by growth proliferation. ${ }^{10}$ Plants initiate communication with microbes by releasing root exudates in rhizosphere. 
The root exudates produced by plants are major attractant for microbes as a source of nutrition to establish themselves in rhizosphere. ${ }^{11,12}$ The carbon rich nutrition such as sucrose derived from plant roots, establishes communication with soil microorganisms. This communication triggers root colonization by microbial species. ${ }^{13}$ The pathogenic soil borne microorganisms primarily colonizes plant roots to initiate infection, however, colonization of plant roots by beneficial rhizospheric microbes prior to pathogens results in competition for ecological niche leading to elimination of later.

Successful root colonization by agriculturally important microorganisms has imparted resistance and tolerance to various ecological stresses. Efficient root colonization by Trichoderma species have demonstrated better resistance toward plant diseases and abiotic stresses via Induced systemic resistance (ISR) and induced systemic tolerance (IST), respectively. ${ }^{14}$ Many studies in literature have also demonstrated that unsuccessful colonization by efficient AIMs result in poor performance. Inefficient plant roots colonization by biocontrol strains of PGPR have been reported to show inconsistent performance in management of soil borne diseases. ${ }^{15,16}$ An inverse correlation between number of beneficial bacteria and number of diseased plants has been documented by Bull et al., ${ }^{17}$ depicting correlation of inefficient root colonization on reduced biocontrol potential of bacteria. ${ }^{15}$ In support of this, study of Guo et al., ${ }^{18}$ suggested that PGPR strains that possess ability to produce inhibition zone and colonize roots efficiently can be a promising biocontrol agents. Efficient plant root colonization by beneficial microorganisms therefore, is the most crucial and prime step for biocontrol of plant diseases in addition to plant growth promotion; amelioration of abiotic stress and bioremediation (Figure 1). The motility, synthesis of extracellular polysaccharides and microbial population density are some major factors that determine the potential of AIMs in successful root colonization. The functional activities performed by bacteria and filamentous fungi to colonize plant roots include formation of microcolonies or biofilms and coordination with each other by the use of system of stimuli "Quorum Sensing" (QS). ${ }^{19,20}$ Quorum Sensing is a mechanism of cell-to-cell communication, which induces gene expressions and regulates process of root colonization. ${ }^{21}$ The biocontrol strain Pseudomonas fluorescens 2P24 employ QS system and production of antibiotics for controlling pathogens. However, the mutant of $P$. fluorescens with deletion of pcoI gene, devoid of QS mechanism was found to produce antibiotics including 2,4-DAPG, hydrogen cyanide and siderophore but lacks the ability to form biofilm, rhizosphere colonization and biocontrol of wheat take-all and tomato bacterial wilt. ${ }^{22}$

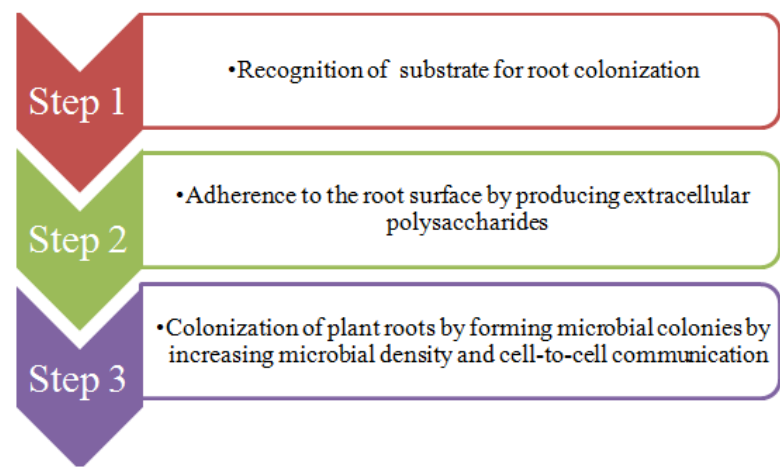

Figure I Showing steps involved in root colonization.

\section{Conclusion}

The present review is an attempt to signify role of root colonization by beneficial rhizospheric microorganisms in protecting crops from ecological stresses and plant growth promotion. It also outlines the mechanism involved by them in root colonization. Beneficial rhizospheric microorganisms display their plant growth promoting and biocontrol traits on successful colonization of plant roots. The plant root colonization involves series of steps that necessitate adhesion to the plant surface by production of exopolysaccharides and formation of biofilm. Successful root colonization determines the efficacy of microbial isolates. Therefore for efficiently harnessing potential of rhizospheric microbes, in-depth understanding of mechanisms involved by these microorganisms against multiple biotic and abiotic stress is needed. Understanding and further exploring mechanisms involved in root colonization at molecular level could be significant for strengthening biotechnological techniques and their application in actual environmental condition for sustainable agriculture.

\section{Acknowledgements}

None.

\section{Conflict of interest}

The author declares there is no conflict of interest.

\section{References}

1. Kashyap PL, Rai P, Srivastava AK, et al. Trichoderma for climate resilient agriculture. World J Microbiol Biotechnol. 2017;33:155.

2. Sachdev S, Singh RP. Studies on trends in use of pesticides and fertilizers for tomato cultivation in the vicinity of Lucknow, India. International Journal of Science Technology and Society. 2016;2(1-2):49-54.

3. Sachdev S, Singh RP. Current challenges, constraints and future strategies for development of successful market for biopesticides. Climate Change and Environmental Sustainability. 2016;4(2):129-136

4. Ehrlich PR, Ehrlich AH. Population, Resources, and the Faith-Based Economy: the Situation in 2016. Biophys Econ Resour Qual. 2016;1:3.

5. Godfray HCJ, Beddington JR, Crute IR, et al. Food security: the challenge of feeding 9 billion people. Science. 2010;327:812-818.

6. Rockstrom J, Williams J, Daily G, et al. Sustainable intensification of agriculture for human prosperity and global sustainability. Ambio. 2017;46(1):4-17.

7. Singh DP, Singh HB, Prabha R. Microbial Inoculants in Sustainable Agricultural Productivity. Research perspective India. 2016;(1).

8. Harman GE. Trichoderma- not just for biocontrol anymore Phytoparasitica. 2011;39(2):103-108.

9. Benitez T, Rincon AM, Limon MC, et al. Biocontrol mechanisms of Trichoderma strains. International Microbiology. 2004;7:249-260.

10. Berg G. Plant-microbe interactions promoting plant growth and health: perspectives for controlled use of microorganisms in agriculture. Applied Microbiology and Biotechnology. 2009;84(1):11-18.

11. Hermosa R, Viterbo A, Chet I et al. Plant-beneficial effects of Trichoderma and of its genes. Microbiology. 2012;158:17-25.

12. Druzhinina IS, Seidl-Seiboth V, Herrera-Estrella A, et al. Trichoderma: the genomics of opportunistic success. Nat Rev Microbiol. 2011;9:749759 . 
13. Vargas WA, Mandawe JC, Kenerley CM. Plant-derived sucrose is a key element in the symbiotic association between Trichoderma virens and maize plants. Plant Physiol. 2009;151(2):792-808.

14. Brotman Y, Landau U, Cuadros-Inostroza A, et al. Trichoderma-Plan Root Colonization: Escaping Early Plant Defense Responses and Activation of the Antioxidant Machinery for Saline Stress Tolerance. PLoS Pathog. 20139(3):e1003221.

15. Schippers B, Bakker AW, Bakker PAHM. Interactions of deleterious and beneficial rhizosphere microorganisms and the effect of cropping practices. Annu Rev Phytopathol. 1987;25:339-358.

16. Weller DM. Biological control of soilborne plant pathogens in the rhizosphere with bacteria. Annu Rev Phytopathol. 1988;26:379-407.

17. Bull CT, Weller DM. Thomashow LS. Relationship between root colonization and suppression of Gaeumannomyces graminis var. tritici by Pseudomonas fluorescens strain 2-79. Phytopathol. 1991;81:954-959.
18. Guo JH, Qi HY, Guo YH, et al. Biocontrol of tomato wilt by plant growth-promoting Rhizobacteria. Biological Control. 2004;29(1):66-72.

19. Choudhary DK, Johri BN. Interactions of Bacillus spp. and plants-with special reference to induced systemic resistance (ISR). Microbiol Res. 2009;164:493-513.

20. Velmourougane K, Prasanna R, Saxena AK. Agriculturally important microbial biofilms: present status and future prospects. J Basic Microbiol. 2017;57(7): 548-573

21. Podile AR, Vukanti RVNR, Sravani A, et al. Root Colonization and Quorum Sensing are the Driving Forces of Plant Growth Promoting Rhizobacteria (PGPR) for Growth Promotion. Proc Indian Natn Sci Acad. 2014;80(2):407-413.

22. Wei HL, Zhang LQ. Quorum-sensing system influences root colonization and biological control ability in Pseudomonas fluorescens 2P24. Antonie Van Leeuwenhoek. 2006;89(2):267-80. 